\title{
Urgences
}

\section{Michelle Dubois, Prendre corps, Rimouski, Éditeq, 1986, 80 p. Lucien Cimon}

Numéro 16, mars 1987

D.G. Jones : d'un texte, d'autres

URI : https://id.erudit.org/iderudit/025409ar

DOI : https://doi.org/10.7202/025409ar

Aller au sommaire du numéro

Éditeur(s)

Urgences

ISSN

0226-9554 (imprimé)

1927-3924 (numérique)

Découvrir la revue

Citer ce compte rendu

Cimon, L. (1987). Compte rendu de [Michelle Dubois, Prendre corps, Rimouski, Éditeq, 1986, 80 p.] Urgences, (16), 96-98. https://doi.org/10.7202/025409ar

Ce document est protégé par la loi sur le droit d'auteur. L’utilisation des services d'Érudit (y compris la reproduction) est assujettie à sa politique d'utilisation que vous pouvez consulter en ligne.

https://apropos.erudit.org/fr/usagers/politique-dutilisation/
Cet article est diffusé et préservé par Érudit.

Érudit est un consortium interuniversitaire sans but lucratif composé de l'Université de Montréal, l'Université Laval et l'Université du Québec à Montréal. Il a pour mission la promotion et la valorisation de la recherche. https://www.erudit.org/fr/ 
Je ne crois pas que tout cet enjolivement serve en quoi que ce soit le propos de l'auteure. Il s'agirait plutôt de voir là une concession à la beauté dite poétique.

Il vaut sans doute mieux retenir que Bélisle, quand elle tente de cerner ses propres désirs, quand elle veut en traduire l'obsession, trouve la sobriété d'une écriture parfaitement efficace.
moi
j'en suis sûre peut-être
j'irai bien devant
j'irai bien
devant les traits des géographes

Cette volonté de parvenir à arpenter son propre territoire, cette tension qui mène l'auteure à vouloir aller "où se définit le champ du désir inductif», voilà sans doute ce qui la rend la plus originale. Et la question qu'elle se pose à elle-même trouve dans l'incertitude qu'elle manifeste toute la nervosité de cette écriture:

cassera-t-elle à peine trop

faible

à peine trop pour l'attraction

le désir cette vertèbre déjà presque

fêlée par la tendresse lourde

Quand elle propose au lecteur ce rythme hachuré, ces hésitations dans l'écriture, elle parvient à donner à sa voix la dimension déjà présente d'une auteure qui, de epassions» chargée, «nous» rejoint profondément.

il subsiste malgré nous

d'est en ouest et inversement

quelque odeur dans le tissu des kilomètres

obstinément désirante comme une planète

habitée appelant quelqu'un

jusqu'au coeur qui tressaille

Et c'est là, quand l'auteure multiplie, comme dans ce texte des «Post-scriptum», les lectures possibles, la forme même du poème, qu'elle affirme le plus clairement qu'elle sait, malgré tout, "saisir le moment où l'oeil passe».

Hugues Corriveau

\section{Michelle Dubois: Prendre corps, Rimouski, Édi- teq, 1986, 80 p. (Prix littéraire des Associés 1986)}

Malgré le nombre imposant de feuillets, de brochures, de revues et de recueils qui, chaque année, sont publiés au Québec et qui aspirent à être considérés comme des objets poétiques, on est forcé de dire que la poésie est bien rare aujourd'hui. Écrire, à notre époque, dans notre société férue de spécialisation, est devenu un «métier» exclusif et chaque cénacle obéit aux règles de quelques censeurs intraitables qui contraignent leurs disciples à ressasser sans cesse les mêmes vieilles nouveautés. 
Trop de minettes désincarnées nourries de lieux communs livresques, trof, de producteurs de textes à trous, dessinateurs de parenthèses, de cacheurs de inots mystères, trop de linguistes informatisés, trop d'Arsinoé déguisées en suffragettes, trop de philosophes qui sentent le presbytère, trop de camarades à la morale vociférante, trop de violeurs de la page blanche qui n'écrivent que pour la critique qu'ils feront eux-mêmes avec brio troquent le bonnet d'âne pour l'auréole de poète, parasitent les ondes, polluent le genre et incitent le lecteur de bonne volonté à tuer son ennui ou, pire, son dégoût, en collectionnant des vidéoclips ou des bouteilles vides.

C'est avec son corps que l'on parle, c'est avec lui que l'on écoute; c'est avec le corps que les poèmes s'écrivent parce que c'est avec le corps qu'il nous est donné de nous approprier le réel, de vivre. C'est ce dont témoigne hautement Michelle Dubois dans son dernier ouvrage.

Le recueil Prendre corps marque un moment capital dans la démarche de cette auteure en ceci qu'il pourrait bien clore une recherche amorcée depuis longtemps et qu'il insiste sur une nécessité première qui doit animer quiconque veut accéder vêritablement au "discours poétique» en donnant à ce principe la clarté d'une évidence.

Tout évident qu'il soit, cet impératif de posséder son propre corps n'en est pas moins difficile à conquérir, car il implique une remise en question fondamentale de chaque geste et de chaque attitude acquise ou imposée, une "réappropriation» de chaque objet meublant son univers. C'est dans l'attitude maintenue tout au long de cette lutte que réside l'originalité de l'approche de Dubois et c'est sa façon de nous en retracer les péripéties qui nous révèle les grandes qualités de son art d'écrire et la profondeur de son expérience de vie. Prendre corps, c'est l'histoire d'une fermme (l'histoire de tout être humain aussi) qui atteint sa pleine maturitë et qui fait, en toute lucidité, un premier véritable bilan de son existence.

«ll est midi» (p. 11)

«J'ai éteint toutes les lampes»

«Je m'emmure» (p. 12).

L'univers s'est rétréci à son insu sans qu'elle résiste. Ses sensations se sont émoussées, se sont éteintes; la vie est devenue un lent et docile apprentissage de la mort. Cette mort qui sait se faire attirante, accueillante: lieu du confort et du repos.

«(...) coussin te reçoit et te garde (...)

Tu reviendras vers lui respirer l'odeur totale des abanbons» (p. 27)

Il serait tentant d'accepter, d'abdiquer: le choix est défendable: il comporte beaucoup d'avantages, surtout si on est une femme. Mais l'envie de vivre a la vie dure, surtout si on est une femme, et la passion est grande et la curiosité...

«Il y avait du bruit quelque part» (p. 12)

"C'est plein de chuchotements dans l'interstice

entre la croûte et le coeur" (p. 17)

"Ça me pinçait le sang pour le réveiller» (p. 12).

Cette lueur de passion qu'on n'a pas su étouffer va déterminer le choix:

«dans le soubresaut j'entends la mémoire

tourner sa voix vers le refus 
égrener son parcours en syncopes

par solidarité» (p. 20, je souligne)

Accepter la réclusion silencieuse, c'est accepter la défaite et inviter les autres à en faire autant; refuser, c'est s'engager dans le «dur plaisir rebelle» d'un combat incertain pour la reconquête de son intégrité. C'est faire à rebours tout le parcours déjà suivi, c'est reprendre ce qu'on avait jeté à la poubelle et reconstruire: reprendre corps: retrouver ses sens et les raviver un à un, explorer les profondeurs du sous-sol pour s'assurer de la vitalité des racines, repasser par la chambre, la cuisine, accéder au grenier des souvenirs pour redonner vie à l'enfance, à ses gestes, à ses rêves, à ses révoltes. Renaître neuve en mai, riche d'un passé à même lequel on s'est reconstruite et d'une sagesse sereine qui nourrit la jeunesse du sang.

Toute intéressante qu'elle soit, cette thématique n'est pas nouvelle en poésie québécoise et ce n'est pas elle qui donne au recueil son originalité. Tout a été dit; c'est la manière de les exprimer qui peut renouveler certaines vérités et c'est par là que Michelle Dubois réussit à composer un univers original en créant son imagerie propre à même les objets les plus communs qui meublent le quotidien de tant de femmes. Son art consiste à doser parfaitement le lyrisme avec une santé qui permet aux situations les plus tragiques de demeurer soutenables et d'être regardées avec une calme lucidité, en évitant de tomber dans les clichés des dialectiques des féministes exaspérées. C'est cette santé qui confère au discours son caractère attachant, son naturel et sa force de conviction.

J'ai aimé Prendre corps. C'est une oeuvre qui sait faire vibrer et faire réfléchir; une oeuvre qui démontre une grande maturité et une bonne maîtrise de l'écriture, particulièrement dans les parties qui adoptent une forme plus proche de la prose; la parole y est plus libre et personnelle, l'émotion plus forte et le propos plus limpide. J'ai particulièrement apprécié qu'un auteur de la région opte de façon délibérée pour écrire son propre livre sans faire de concessions aux savantes modes bien vues dans les cercles fermés et sans oeillades aux critiques officiels.

Lucien Cimon

\section{Mario Cotté: Variations sur des légendes bicoises, Sherbrooke, Naaman, 1986, 66 p.}

Du temps où Patrice de La Tour du Pin frayait encore avec l'irréalité avant d'entreprendre une aventure théologique à la façon de Saint Thomas, il avait écrit (La quête de joie, Gallimard, 1933): "Tous les pays qui n'ont plus de légende / Seront condamnés à mourir de froid...».

La Sologne, certes, ne manque ni de forêts, ni d'étangs, ni de tourbières propres à exciter l'imagination populaire. A ce compte, le paysage majestueux du Bic, P.Q. recèle des mystères autrement plus poétiques.

C'est d'abord ce qu'a voulu nous livrer Mario Cotté, amoureux comme pas un des «fantômes qui font du saute-mouton avec les nuages» (p. 11), de ces récifs qui bordent la côte, de ces caps aux noms troublants, de cette mer qui écume et de ces islets grugés par l'histoire et les marées. 